\title{
PEMBUATAN ALAT BANTU PELEPAS PIN SWING LINK PADA BOLSTER BOGIE KERETA API
}

\author{
Adhitya Bagas Pratama \\ Teknik Mekanika Perkeretaapian \\ Akademi Perkeretaapian Indonesia Akademi Perkeretaapian Indonesia \\ Jalan Tirta Raya I, Madiun (63129) Jalan Tirta Raya I, Madiun (63129) J \\ adhityabagasp@gmail.com \\ fadli@pengajar.ppi.ac.id \\ Fadli Rozaq \\ Teknik Mekanika Perkeretaapian \\ Surjanto \\ Teknik Mekanika Perkeretaapian \\ Akademi Perkeretaapian Indonesia \\ alan Tirta Raya I, Madiun (63129) \\ surjanto@pengajar.ppi.ac.id
}

\begin{abstract}
Train bogie is one of the main components related to passenger safety and comfort that require maintenance. One component of bogie that must be treated is a bolster. In this bolster, there is an important component called the swing link pin that must be removed when starting disassembly. The purpose of this study is to build a swing link pin release tool more effective and more efficient compared to existing tools. The design process of this tool uses the Solidworks 2017 software. The test results show that the pin release tool produced from this study can release the pin faster than the existing tools.
\end{abstract}

Keywords: bogie, train, bolster, swing link, pin release tool

\begin{abstract}
Abstrak
Bogie kereta api merupakan salah satu komponen utama yang terkait keselamatan dan kenyamanan penumpang sehingga membutuhkan perawatan. Salah satu komponen bogie yang harus dirawat adalah bolster. Pada bolster ini terdapat komponen penting bernama pin swing link yang harus dilepas pada saat memulai pembongkaran. Tujuan penelitian ini adalah untuk membuat alat bantu pelepas pin swing link yang lebih efektif dan lebih efisien dibandingkan dengan alat yang sudah ada. Proses desain alat bantu ini menggunakan aplikasi Solidworks 2017. Hasil pengujian menunjukkan bahwa alat bantu pelepas pin yang dihasilkan dari studi ini dapat melepas pin lebih cepat dibandingkan dengan alat yang sudah ada.
\end{abstract}

Kata-kata kunci: bogie, kereta api, bolster, swing link, alat bantu pelepas pin

\section{PENDAHULUAN}

Perawatan adalah kegiatan yang diarahkan pada suatu tujuan guna menjamin kelangsungan fungsional suatu sistem produksi atau peralatan sehingga dapat diperoleh hasil yang sesuai dengan yang dikehendaki. Pelaksanaan perawatan dianggap berhasil apabila sistem dapat melakukan fungsinya sesuai dengan rencana dan tidak mengalami kerusakan selama sistem tersebut berfungsi atau sebelum jangka waktu yang direncanakan (Hidayat dan Mahardiono, 2015). Menurut Peraturan Menteri Perhubungan No. 94 Tahun 2010 Pasal 1 Ayat 4, perawatan sarana merupakan kegiatan yang dilakukan untuk mempertahankan keandalan sarana perkeretaapian agar tetap laik operasi. Perawatan sarana kereta api terdiri atas perawatan harian, perawatan bulanan, perawatan 6 bulanan, dan perawatan tahunan (Pemerintah Republik Indonesia, 2009b). Perawatan tahunan merupakan rangkaian proses perawatan yang paling kompleks karena dilakukan bongkar pasang pada sarana kereta api, dengan salah satu komponen utama pada kereta api yang dilakukan perawatan tahunan adalah bogie (Pemerintah Republik Indonesia, 2009c). 
Bogie adalah susunan perangkat roda, rangka, dan sistem suspensi sebagai suatu kesatuan struktur yang mendukung sarana perkeretaapian saat berjalan di atas jalan rel (Pemerintah Republik Indonesia, 2009a). Fungsi utama bogie adalah menghasilkan fleksibilitas kereta terhadap rel sehingga roda dapat tetap mengikuti arah rel saat melewati tikungan (Laksana, 2016). Bogie terdiri atas dua sistem pemegasan yang berfungsi untuk meredam getaran dan goncangan roda sehingga dapat meningkatkan keamanan dan kenyamanan penumpang (Surahman, 2016).

Kereta api penumpang di Indonesia menggunakan bogie dengan jenis bolster dan non-bolster. Jenis bogie yang memiliki populasi terbanyak di Indonesia adalah bogie bolster yang selain oleh pegas, peredaman getaran dan peredaman goncangannya dibantu oleh bolster. Salah satu jenis bogie bolster adalah Bogie NT-11 (K-5), buatan Nippon Sharyo, Jepang (PT INKA, 2015). Bogie jenis K5 ini merupakan bogie kereta api dengan sistem suspensi, yang terdiri atas 3 jenis pegas, yaitu pegas pendukung, pegas ayun dalam, dan pegas ayun luar. Apabila pegas mengalami kegagalan secara tiba-tiba, akan terjadi kecelakaan atau anjloknya kereta dari lintasan rel (Abdillah, 2010). Untuk sistem pemegasan menggunakan pegas primer dan pegas sekunder yang dilengkapi dengan peredam arah vertikal (shock absorber), jarak titik tumpu adalah $1.520 \mathrm{~mm}$ dan jarak antargandar roda adalah $2.200 \mathrm{~mm}$ (Novianti dan Hanhan, 2018).

Dalam perawatan bogie, terdapat komponen utama yang harus dilepas terlebih dahulu. Komponen tersebut bernama bolster yang dikunci menggunakan pin swing link. Pin swing link adalah pin yang berfungsi untuk mengunci spring plank dengan swing link. Bolster menggunakan pegas tekan yang berfungsi untuk menekan ke atas upper bolster dan menekan ke bawah spring plank sehingga pin pengunci spring plank dan swing link sulit dilepas.

Di Balai Yasa Surabaya Gubeng, proses pelepasan pin ini menggunakan alat konvensional, seperti terlihat pada Gambar 1. Alat tersebut berbentuk besi ulir, dengan bagian atas dan bagian bawah dikunci oleh baut atau mur. Baut atau mur dikencangkan menggunakan kunci pas ukuran M46 untuk menekan pegas ulir serta dikendorkan murnya untuk melepas alat tersebut. Cara kerja alat tersebut adalah menekan pegas ulir agar kedudukan lubang spring plank sejajar dengan lubang swing link. Pin dapat dilepaskan dari lubang tersebut jika tidak mendapat gaya-gaya dari spring plank maupun dari swing link.

Penggunaan alat di Balai Yasa Surabaya Gubeng membutuhkan waktu (6-8) menit dari persiapan alat sampai pin bisa lepas. Memutar kunci pas ukuran 46 untuk mengencangkan mur guna menekan pegas ulir cukup membutuhkan tenaga karena konstanta pegas ulir yang harus ditekan mur tersebut mencapai $36.000 \mathrm{~N}$ atau $3.600 \mathrm{~kg}$. Pada tahun 2018, jumlah perawatan kereta api di Balai Yasa Surabaya Gubeng sudah mencapai angka 246 kereta, dan pada tahun 2019 jumlah perawatan kereta api ini mungkin meningkat. Hal ini akan memengaruhi kegiatan perawatan di Balai Yasa Surabaya Gubeng. Semakin banyak permintaan akan perawatan kereta api, semakin cepat pula pekerjaan yang harus dilakukan, sehingga dibutuhkan alat yang lebih efisien dan efektif untuk memudahkan teknisi pada saat melakukan perawatan kereta api, khususnya saat melepas pin swing link. 


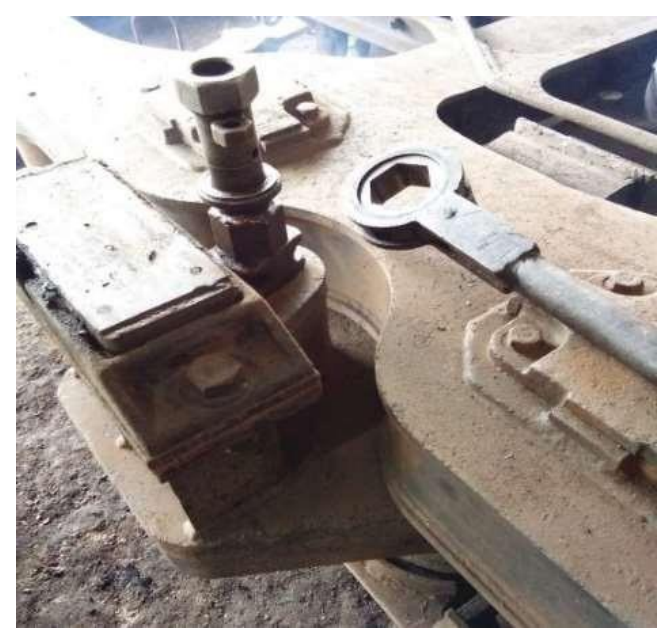

Gambar 1 Alat Pelepas Pin di Balai Yasa

Pada penelitian ini dilakukan pengumpulan data primer dan data sekunder. Data primer diperoleh langsung dari lapangan, yang terdiri atas wawancara dengan pegawai Balai Yasa Surabaya Gubeng, praktik pelepasan pin swing link di Balai Yasa Surabaya Gubeng, observasi langsung ke PT INKA, serta perancangan, pembuatan, dan pengujian konstruksi alat bantu pelepas pin swing link di workshop Akademi Perkeretaapian Indonesia. Sedangkan data sekunder diperoleh dari referensi-referensi, seperti buku, jurnal, dan internet.

\section{PROSES PEMBUATAN}

Pembuatan alat bantu pelepas pin swing link ini menggunakan metode waterfall, yang merupakan suatu metode melalui proses pengembangan secara berurutan, dengan kemajuan proses terus-menerus mengalir ke bawah, seperti air terjun, dengan fase-fase perencanaan atau persyaratan, desain, pembuatan konstruksi, pengujian, dan perawatan (Tristianto, 2018). Pembuatan alat bantu pelepas pin swing link pada bolster bogie kereta melalui beberapa tahapan. Tahap pertama adalah membuat desain kontruksi alat menggunakan aplikasi Solidworks 2017, kemudian dilanjutkan degan pembuatan konstruksi alat. Setelah alat bantu pelepas pin swing link jadi, dilakukan pengujian terhadap bogie kereta tipe TB 398.

\section{Desain}

Desain awal alat ditunjukkan pada Gambar 2a. Desain alat ini mengalami perubahan karena desain awal tidak dapat diterapkan atau tidak dapat diletakkan pada permukaan bolster yang akan menjadi tempat diletakkannya alat tersebut. Jika menggunakan desain awal, dimensi bolster terlalu sempit, sehingga alat tidak dapat masuk ke bagian bolster atas. Untuk mengatasi hal tersebut dibuat desain akhir, yang mana alat ditambah dengan konstruksi bawah untuk memperluas permukaan alat, seperti terlihat pada Gambar $2 b$ dan Gambar 3. 


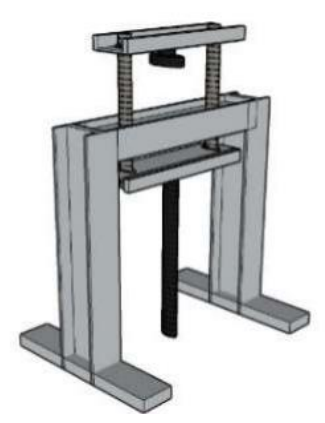

(a) Desain Awal

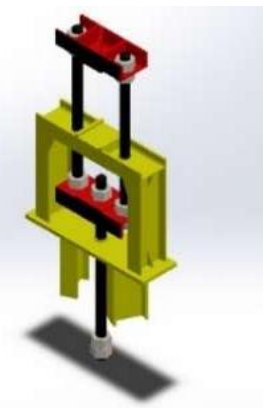

(b) Desain Akhir

Gambar 2 Perbandingan Desain Awal dan Desain Akhir

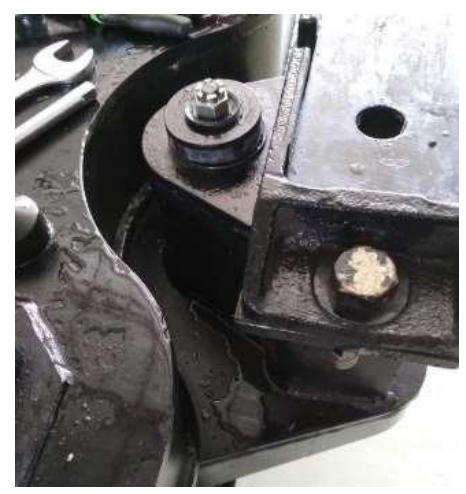

Gambar 3 Daerah Bolster Tempat Peletakan Alat

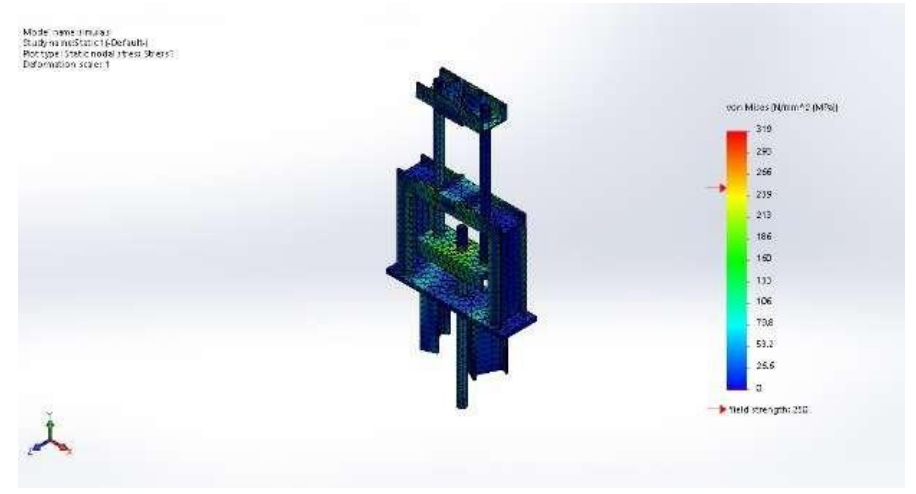

Gambar 4 Simulasi Pembebanan Alat

Simulasi dengan menggunakan aplikasi Solidworks 2017 dimaksudkan untuk menguji kekuatan alat yang didesain. Dari proses simulasi ini diketahui bahwa bahan yang digunakan untuk membuat alat memenuhi persyaratanan karena tegangan yang diterima bahan masih lebih kecil daripada tegangan izin bahan. Terlihat pada Gambar 4 dan Gambar 5 bahwa bahan yang digunakan banyak yang berwarna biru dan sedikit yang berwarna hijau atau kuning. Defleksi atau deformasi bahan masih aman, karena defleksi yang terjadi kurang dari $1 \mathrm{~cm}$. 


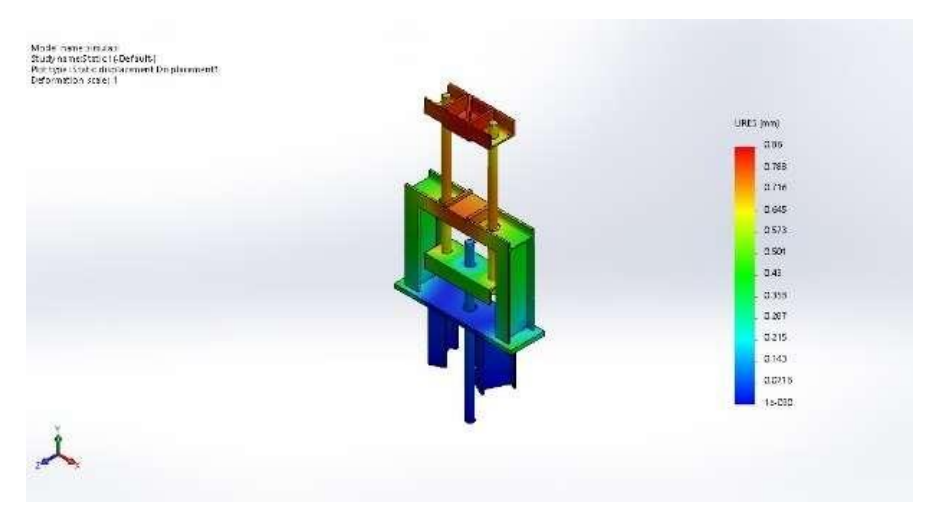

Gambar 5 Hasil Simulasi terhadap Defleksi Bahan

\section{Produksi Alat}

Produksi konstruksi alat bantu pelepas pin swing link pada perawatan bolster bogie kereta api terdiri atas beberapa tahapan. Tahapan tersebut adalah persiapan produksi, pembuatan konstruksi bawah, pembuatan konstruksi tengah, pembuatan konstruksi atas, dan finishing.

Persiapan produksi membutuhkan beberapa bahan dan alat. Bahan dan alat yang akan dipakai harus dipersiapkan sesuai dengan rancangan desain yang sudah dibuat, karena dapat menghemat waktu, biaya, dan tenaga. Komponen tersebut adalah:

a) Baja profil WF-beam 100 ukuran $200 \mathrm{~mm}$ sebanyak 2 buah, ukuran $310 \mathrm{~mm}$ sebanyak 2 buah, ukuran $400 \mathrm{~mm}$ sebanyak 1 buah;

b) Baja pelat $450 \mathrm{~mm} \times 130 \mathrm{~mm} \times 120 \mathrm{~mm}$ sebanyak 1 buah;

c) Baja pelat berbentuk segitiga siku ukuran $50 \mathrm{~mm}$ x $25 \mathrm{~mm}$ sebanyak 12 buah;

d) Baja profil U:kanal u 100 ukuran $250 \mathrm{~mm}$ sebanyak 2 buah;

e) Baja tulangan polos:baja tulangan beton polos diameter $30 \mathrm{~mm}$ ukuran $570 \mathrm{~mm}$ sebanyak 2 buah, ukuran $640 \mathrm{~mm}$ sebanyak 1 buah;

f) Mur tipe M30 sebanyak 11 buah;

g) Dongkrak hidrolik botol kapasitas maksimal 5 ton;

h) Peralatan bantu, seperti mesin gerinda, mesin bor, palu terak, kacamata las, mesin las, penggaris siku, penitik, meteran, dan alat kikir; dan

i) Alat pelindung diri, seperti helm pelindung, rompi, wearpack, sarung tangan, kaca mata pelindung, earplug, dan safety shoes.

Semua bahan yang terbuat dari besi digerinda untuk menghaluskan permukaannya dan untuk membuat ukuran bahan tersebut sesuai dengan desain yang telah dibuat. Dari hasil produksi alat bantu pelepas pin swing link, didapat produk yang sesuai dengan desain.

Pembuatan konstruksi bawah dimulai dengan membuat Baja WF berukuran panjang $200 \mathrm{~mm}$ sebanyak 2 buah. Pemotongan dan penghalusan permukaan dilakukan dengan menggunakan gerinda. Baja WF dibuat sesuai dengan ukuran, kemudian dilakukan pembuatan ukuran besi pelat dengan gerinda. Besi pelat dibawa ke bengkel bubut untuk dilakukan pengeboran atau pembuatan lubang pada besi pelat. Setelah besi pelat selesai dibubut, dilakukan perakitan antara Baja WF dengan pelat besi. Penyambungan dilakukan dengan 
cara pelat besi diberi tanda atau garis untuk menggabungkan Baja WF dengan pelat. Pemasangan pelat dan Baja WF dilakukan dengan cara digabungkan pojok-pojok, seperti pada Gambar 6.

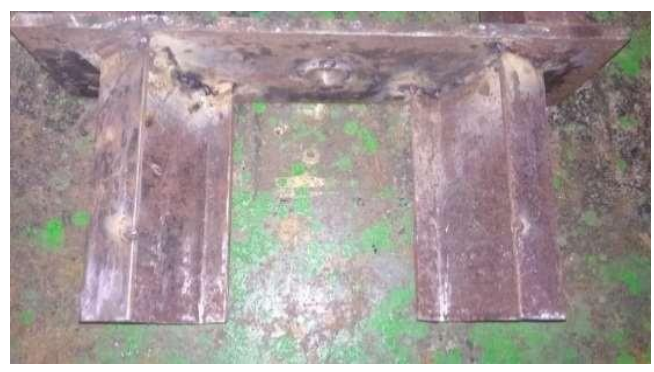

Gambar 6 Bentuk Konstruksi Rangka Bawah

Kontruksi tengah dibuat dari Baja WF sesuai dengan ukuran, kemudian Baja WF bagian melintang yang berukuran $400 \mathrm{~mm}$ dibawa ke bengkel bubut untuk dilakukan pengeboran. Setelah Baja WF melintang dibor, Baja WF dengan ukuran $310 \mathrm{~mm}$ digabung dengan Baja WF melintang tersebut. Penggabungan Baja WF ini dilakukan dengan cara dilas pojok-pojok, sepert yang terlihat pada Gambar 7.

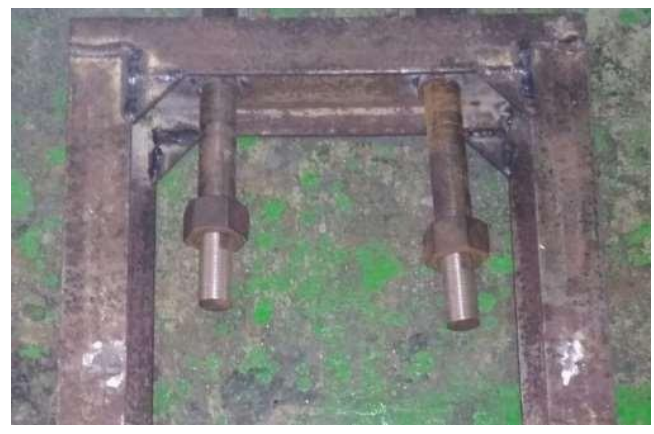

Gambar 7 Bentuk Konstruksi Tengah

Pembuatan konstruksi atas dilakukan dengan penambahan pelat untuk penguat pada tiap baja profil U 100, supaya baja profil U tersebut kuat saat mendapat tekanan dari gaya tekan dongkrak. Setelah semua baja profil U ditambah penguat, baja tulangan beton polos dengan rukuran $570 \mathrm{~cm}$ dimasukkan pada baja profil $\mathrm{U}$ bagian atas melalui lubang. Baja tulangan beton polos tersebut dikencangkan menggunakan mur (lihat Gambar 8).

Perakitan komponen dilakukan jika konstruksi bawah dan konstruksi tengah sudah dilas permanen. Pengelasan juga dilakukan dengan cara mengelas tiap pojok-pojok bagian untuk memastikan penempatan konstruksi tersebut sudah sesuai dengan rancangan. Selanjutnya konstruksi tersebut dilas secara permanen (lihat Gambar 9). Baja tulangan beton polos yang sudah terpasang di Kanal $U$ atas dimasukkan ke konstruksi tengah melalui lubang. Kemudian Kanal U tersebut dikunci dengan menggunakan mur, seperti terlihat pada Gambar 10. 


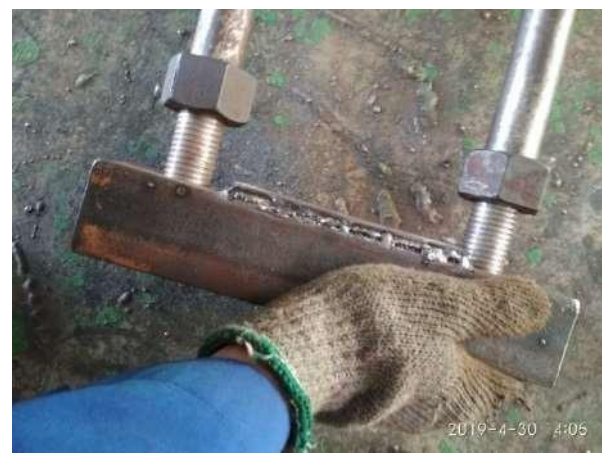

Gambar 8 Bagian Konstruksi Atas

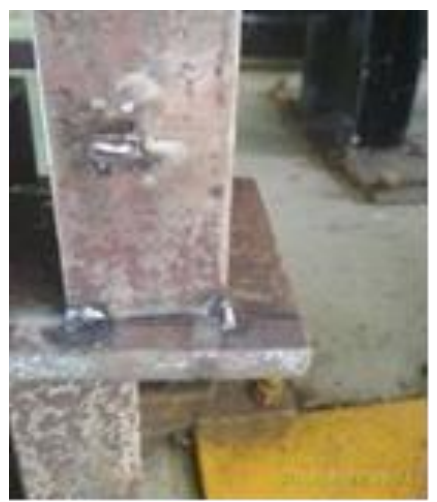

Gambar 9 Perakitan Konstruksi Tengah dan Konstruksi Atas

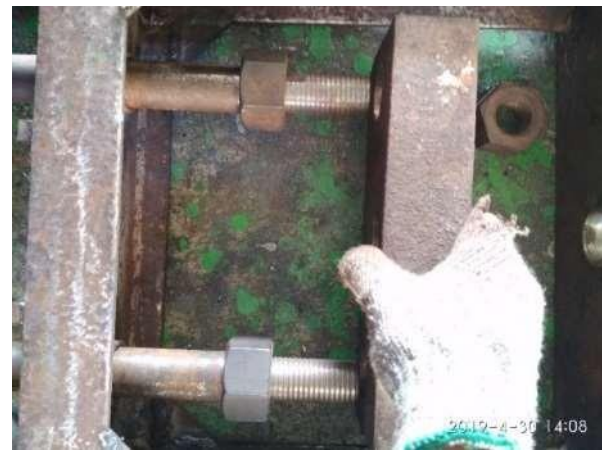

Gambar 10 Perakitan Konstruksi Atas ke Konstruksi Tengah

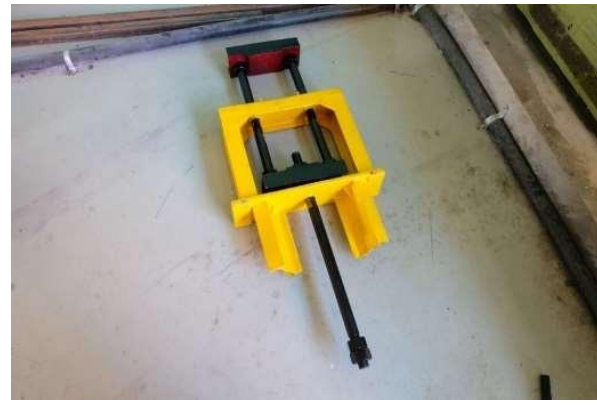

Gambar 11 Bentuk Alat Bantu Pelepas Pin 
Pekerjaan finishing dilakukan setelah semua bagian digabung. Pada tahap ini dilakukan pengecekan kembali hasil las, penambahan dudukan dongkrak pada konstruksi tengah alat, dan pengecatan untuk memperindah penampilan. Bentuk akhir alat yang telah diproduksi ini dapat dilihat pada Gambar 11.

\section{PROSES PENGUJIAN}

\section{Pengujian}

Pengujian dilakukan untuk mengetahui apakah alat yang dibuat dapat berfungsi dengan baik. Parameter yang menjadi tolok ukur alat dapat berfungsi dengan baik adalah dapat membantu melepas pin swing link dengan lebih efisien dan lebih efektif daripada alat yang sebelumnya. Pengujian dilakukan di workshop Akademi Perkeretaapian Indonesia pada bogie K5 TB-398. Hasil yang didapat dari pengujian ini berupa perbandingan waktu yang digunakan terhadap jumlah pin yang dapat dilepas.

\section{Hasil}

Dari hasil pengujian fungsi alat bantu pelepas pin swing link pada bolster bogie diperoleh data yang terdapat pada Tabel 1, Tabel 2, dan Gambar 12. Hasil pengujian tersebut menunjukkan bahwa waktu rata-rata yang dibutuhkan untuk melepas 1 buah pin swing link adalah (2-3) menit, atau lebih cepat daripada alat yang berada di Balai Yasa Surabaya Gubeng, yang membutuhkan waktu (6-8) menit. Jumlah rata-rata pin yang didapat dalam waktu 6 menit dengan menggunakan alat bantu pelepas pin swing link dengan tenaga hidrolik adalah 2,4 buah pin, yang dibulatkan menjadi 2 buah. Jumlah pin bervariasi karena pengujian dilakukan oleh orang yang berbeda, dengan kemampuan dan pengetahuan yang berbeda pula. Hasil pengujian ini menunjukkan bahwa alat yang dibuat pada studi ini lebih efektif dan efisien dibandingkan alat yang sudah ada.

Tabel 1 Rekapitulasi Hasil Pengujian

\begin{tabular}{ccccc}
\hline \multirow{2}{*}{$\begin{array}{c}\text { Jenis } \\
\text { Pengujian }\end{array}$} & \multicolumn{2}{c}{ Referensi Standar Alat Manual } & \multicolumn{2}{c}{ Hasil Pengujian } \\
\cline { 2 - 5 } & $\begin{array}{c}\text { Waktu yang } \\
\text { Dibutuhkan }\end{array}$ & $\begin{array}{c}\text { Jumlah Pin } \\
\text { yang Dilepas }\end{array}$ & $\begin{array}{c}\text { Waktu yang } \\
\text { Dibutuhkan }\end{array}$ & $\begin{array}{c}\text { Jumlah Pin } \\
\text { yang Dilepas }\end{array}$ \\
\hline Ke-1 & $6-8$ menit & 1 buah & 2 menit & 1 buah \\
Ke-2 & $6-8$ menit & 1 buah & 3 menit & 1 buah \\
Ke-3 & $6-8$ menit & 1 buah & 2,5 menit & 1 buah \\
Ke-4 & $6-8$ menit & 1 buah & 2,5 menit & 1 buah \\
Ke-5 & $6-8$ menit & 1 buah & 2 menit & 1 buah \\
\hline
\end{tabular}

Dibandingkan dengan alat yang sudah ada, alat bantu pelepas pin swing link yang dihasilkan dari studi ini memiliki beberapa kelebihan, yaitu tenaga yang dibutuhkan lebih efisien karena menggunakan tenaga dongkrak, waktu untuk melepas pin lebih singkat, perawatannya mudah, dimensi alat tidak terlalu besar dan sesuai dengan kebutuhan, serta dibuat dari bahan yang mudah didapat di pasaran. Sedangkan kekurangannya adalah beratnya 
yang mencapai sekitar $44 \mathrm{~kg}$ sehingga membutuhkan 2 orang untuk menggunakan alat tersebut dan belum dilakukan uji kekuatan bahan, sehingga kekuatan bahan yang sebenarnya belum diketahui.

Tabel 2 Perbandingan Jumlah Pin yang Dilepas

\begin{tabular}{ccccc}
\hline No. & Pengujian & $\begin{array}{c}\text { Waktu } \\
\text { (menit) }\end{array}$ & $\begin{array}{c}\text { Jumlah Pin dengan } \\
\text { Alat Manual } \\
\text { (buah) }\end{array}$ & $\begin{array}{c}\text { Jumlah Pin dengan } \\
\text { Alat Hidrolik } \\
\text { (buah) }\end{array}$ \\
\hline 1 & Pengujian ke-1 & 6 & 1 & 3 \\
2 & Pengujian ke-2 & 6 & 1 & 2 \\
3 & Pengujian ke-3 & 6 & 1 & 2 \\
4 & Pengujian ke-4 & 6 & 1 & 2 \\
5 & Pengujian ke-5 & 6 & 1 & 3 \\
\hline
\end{tabular}

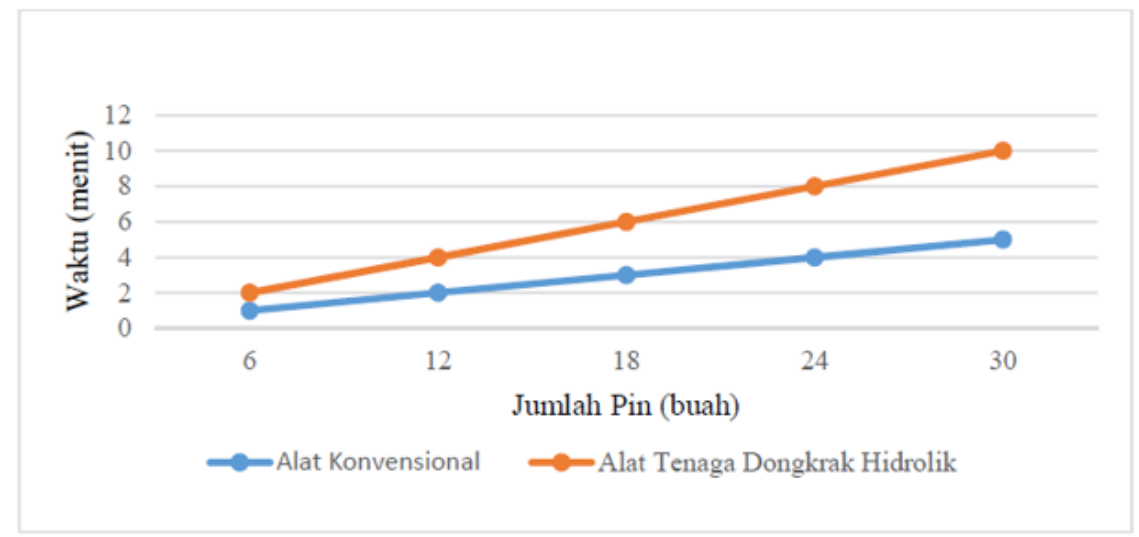

Gambar 12 Perbandingan Hasil Kerja Alat

\section{KESIMPULAN}

Pada studi ini dilakukan penelitian dan pembuatan alat bantu pelepas pin swing link pada bolster bogie kereta api. Desain alat bantu tersebut menggunakan aplikasi Solidworks 2017, untuk mendesain bentuk dan dimensi yang sesuai dengan dimensi bolster bogie, sehingga alat yang dihasilkan dapat diletakkan di bolster bogie.

Proses pembuatan bantu pelepas pin swing link dilakukan melalui beberapa tahapan, yaitu persiapan produksi, pembuatan konstruksi bawah, pembuatan konstruksi tengah, pembuatan konstruksi atas, perakitan semua konstruksi, dan finishing konstruksi. Hasil pengujian terhadap fungsi alat yang dihasilkan menunjukkan bahwa alat yang dibuat pada studi ini lebih efektif dan efisien dibandingkan alat yang sudah ada.

\section{DAFTAR PUSTAKA}

Abdillah, F. 2010. Analysis Kegagalan Komponen Pegas Ulir Luar K5 pada Bogie Kereta Api. Semarang: IKIP Vetran. 
Hidayat, T. dan Mahardiono, N.A. 2015. Evaluasi Perawatan Sarana Perkeretaapian di PT Kereta Api Indonesia (Persero). Bandung: Balai Pengembangan Instrumentasi Lembaga Ilmu Pengetahuan Indonesia.

Industri Kereta Api, PT. 2015. Mengenal Istilah Bogie pada Kereta Api Bagian 1. (Online), (https://www. inka.co.id/berita/58, diakses 3 Januari 2019).

Kementerian Perhubungan. 2010. Peraturan Menteri Perhubungan Nomor PM 94 Tahun 2010 tentang Tenaga Perawatan Sarana Perkeretaapian. Lembaran RI Tahun 2010 Pasal 1 Ayat 4. Jakarta.

Laksana, B.A. 2016. Simulasi Perancangan Smart Temporary Bogie di PT Inka (Persero). Tesis tidak diterbitkan. Surabaya: Institut Bisnis dan Informatika, STIKOM.

Novianti dan Hanhan, M. 2018. Pembangunan Aplikasi Multimedia sebagai Media Pembelajaran Bogie Kereta Api (Studi Kasus di Balai Pusat Pendidikan dan Pelatihan PT Kereta Api Indonesia). Tesis tidak diterbitkan. Bandung: Unikom.

Pemerintah Republik Indonesia. 2009a. Peraturan Pemerintah Nomor 56 Tahun 2009 tentang Penyelenggaraan Perkeretaapian. Lembaran RI Tahun 2009 Pasal 184 Ayat 1 Huruf c. Jakarta.

Pemerintah Republik Indonesia. 2009b. Peraturan Pemerintah Nomor 56 Tahun 2009 tentang Penyelenggaraan Perkeretaapian. Lembaran RI Tahun 2009 Pasal 223 Ayat 1. Jakarta.

Pemerintah Republik Indonesia. 2009c. Peraturan Pemerintah Nomor 56 Tahun 2009 tentang Penyelenggaraan Perkeretaapian. Lembaran RI Tahun 2009 Pasal 232 Ayat 2. Jakarta.

Surahman. 2016. Automatic Clamping System Side Frame Bogie pada Kereta Penumpang Bangladesh PT Inka (Persero) Madiun. Tesis tidak diterbitkan. Surabaya: Institut Bisnis dan Informatika, STIKOM.

Tristianto, C. 2018. Penggunaan Metode Waterfall untuk Pengembangan Sistem Monitoring dan Evaluasi Pembangunan Pedesaan. Jurnal Teknologi Informasi ESIT, XII (1): 822. 